\title{
Surface properties and porosity of highly porous, nanostructured cellulose II particles
}

\author{
Marco Beaumont $(\mathbb{D} \cdot$ Anett Kondor - Sven Plappert - Claudia Mitterer • Martina Opietnik • \\ Antje Potthast • Thomas Rosenau
}

Received: 22 August 2016/Accepted: 6 October 2016/Published online: 15 October 2016

(C) The Author(s) 2016. This article is published with open access at Springerlink.com

\begin{abstract}
Recently, a new member of the nanocellulose family was introduced, a cellulose II gel consisting of nanostructured and spherical particles. In this study, we compared two different drying techniques to obtain highly porous powders from this gel with preserved meso- and macroporous nanostructure: first, freeze-drying after solvent exchange to $t \mathrm{BuOH}$ and second, supercritical drying of the respective EtOH alcogel. The approaches yielded aerogel powders with surface areas of 298 and $423 \mathrm{~m}^{2} / \mathrm{g}$, respectively. Both powders are amphiphilic and possess energetically heterogeneous surfaces with dominating dispersive term of the surface energy in
\end{abstract}

Electronic supplementary material The online version of this article (doi:10.1007/s10570-016-1091-y) contains supplementary material, which is available to authorized users.

M. Beaumont $\cdot$ S. Plappert - A. Potthast $\cdot$ T. Rosenau Department of Chemistry, Division of Chemistry of Renewable Resources, University of Natural Resources and Life Sciences Vienna (BOKU), Konrad-LorenzStraße 24, 3430 Tulln, Austria

\footnotetext{
A. Kondor

Surface Measurement Systems Ltd., Rosemont Rd,

Wembley, London HA0 4PE, UK

C. Mitterer

Polymer \& Composite Engineering (PaCE) Group, Institute for Materials Chemistry and Research, Faculty of Chemistry, University of Vienna, Währingerstr. 42, 1090 Vienna, Austria
}

the range of $50-52 \mathrm{~mJ} / \mathrm{m}^{2}$, as determined by a combination of physicochemical surface characterization techniques, such as iGC, BET and SEM. Despite the lower surface area, the cheaper and more widespread method, freeze-drying, yields a more polar and reactive cryogel.

Keywords Nanocellulose $\cdot$ Lyocell $\cdot$ Inverse gas chromatography $\cdot$ Thermoporosimetry $\cdot$ Freezedrying $\cdot$ Supercritical drying

$\begin{array}{ll}\text { Abbreviations } \\ \mathrm{CNF} & \text { Cellulose nanofibrils } \\ \mathrm{FD} & \text { Freeze-drying } \\ \mathrm{scCO}_{2} & \text { Supercritical } \mathrm{CO}_{2}\end{array}$

M. Opietnik

Lenzing AG, Werkstrasse 2, 4860 Lenzing, Austria

T. Rosenau

Johan Gadolin Process Chemistry Centre, Åbo Akademi

University, Porthansgatan 3, 20500 Åbo/Turku, Finland

T. Rosenau ( $\square)$

1190 Vienna, Austria

e-mail: thomas.rosenau@boku.ac.at 
$t \mathrm{BuOH}$ tert-Butanol

iGC Inverse gas chromatography

SEM Scanning electron microscopy

Nanostructured materials have become an important aspect in cellulose research. The distinct properties of nanocelluloses open a wide field of applications in composites (Cai et al. 2012; Li et al. 2014), insulation (Hayase et al. 2014; Kobayashi et al. 2014), packaging (Aulin et al. 2010; Lavoine et al. 2014), tissue engineering (Domingues et al. 2014; Markstedt et al. 2015) and many other utilization ways (Habibi et al. 2010; Lin et al. 2012). Nevertheless, drying of nanocelluloses with retention of their unique properties, in particular the high surface areas, remains a difficult and important challenge. The drying is not only required for some chemical modifications using water-sensitive components, but also impacts the economic and logistic issues (transportation of larger amounts), keeping in mind that most nano-structured gels consist of 95-99 \% water.

In this contribution, we will focus on the recently reported cellulose II gel, TENCEL ${ }^{\circledR}$ gel $^{1}$ (Männer et al. 2015; Beaumont et al. 2016). This cellulose gel is obtained from the lyocell process and particularly sensitive to drying conditions due to its morphology consisting of spherical particles. This makes it a good reference material to compare drying techniques and transfer the results to other cellulosic nanomaterials. As reported in the literature, the nanostructure of this cellulose II gel can be preserved by a solventexchange to $t \mathrm{BuOH}$ and subsequent freeze-drying, yielding aerogels with a high surface area of $298 \mathrm{~m}^{2} / \mathrm{g}$ (Beaumont et al. 2016). By contrast, freeze-drying from the hydrogel gives a sheet-like, non-porous structure due to ice crystal formation. The ice crystals act as templates to self-assemble cellulose particles into the freezing direction (Han et al. 2013). In contrast to that, freeze-drying from $t \mathrm{BuOH}$ prevents the formation of ice crystals artifacts (Wheeler et al. 1975) and is thus superior with regard to preserving the gel structure (Cai et al. 2008). This freeze-drying method was also used to obtain aerogels with surface areas of $284-349 \mathrm{~m}^{2} / \mathrm{g}$ starting from cellulose nanofibrils (CNF) (Sehaqui et al. 2011; Saito et al. 2011; Nemoto et al. 2015). Apart from freeze-drying,

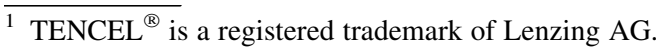

cellulose suspensions can be as well dried by airdrying or spray-drying (Peng et al. 2012; Rämänen et al. 2012; Ganesan et al. 2016). These methods yield xerogels which differ quite drastically from the aerogels reported here: they are denser and have smaller surface areas because of shrinkage and resulting particle agglomeration in the drying process (Aegerter et al. 2011).

We compared freeze-drying of the respective $t \mathrm{BuOH}$ gel (FD/t $\mathrm{BuOH}$ sample) with the benchmark technique: supercritical $\mathrm{CO}_{2}$ drying of the EtOH lyogel $\left(\mathrm{scCO}_{2} / \mathrm{EtOH}\right.$ sample). Surface morphology, porosity and surface area were compared by scanning electron microscopy, thermoporosimetry and nitrogen sorption experiments. Surface heterogeneity, surface energetics and surface chemistry were studied by inverse gas chromatography (iGC).

Figure 1 shows a comparison of the pore data of the two samples obtained by either freeze-drying (FD/ $t \mathrm{BuOH})$ or supercritical drying $\left(\mathrm{scCO}_{2} / \mathrm{EtOH}\right)$. As indicated in the sample name, in both cases a preceding solvent-exchange step was mandatory, either to $t \mathrm{BuOH}$ or to EtOH. The SEM micrographs of both samples show a preserved nanostructure (higher magnification in Figure S2). The aerogels are composed of particles with average sizes of $7.0 \pm 1.9$ and $10.1 \pm 1.8 \mu \mathrm{m}$ in the cases of $\mathrm{FD} / \mathrm{tBuOH}$ and $\mathrm{scCO}_{2} / \mathrm{EtOH}$, respectively. Figure S1 compares both particle distributions to the never-dried gel: we can conclude that supercritically dried powder is very similar to the starting gel, whereas the particle size of $\mathrm{FD} / \mathrm{t} \mathrm{BuOH}$ is shifted to lower values. Nitrogen sorption experiments showed the supercritically dried sample to feature a much higher surface area $\left(423 \mathrm{~m}^{2} /\right.$ g) than the freeze-dried sample $\left(298 \mathrm{~m}^{2} / \mathrm{g}\right)$. This is reasoned by the higher pore volume of $\mathrm{scCO}_{2} / \mathrm{EtOH}$ in the mesoporous $(2-50 \mathrm{~nm})$ and macroporous (larger than $50 \mathrm{~nm}$ ) region, as shown in the pore size distributions obtained by nitrogen sorption and thermoporosimetry (Fig. 1). Surface-to-volume ratios of $\mathrm{FD} / \mathrm{tBuOH}$ and the never-dried gel from SAXS measurements (Beaumont et al. 2016) had already demonstrated that freeze-drying of the cellulose II gel reduced the surface area of the gel. Furthermore, the average pore diameter calculated from the thermoporosimetry pore size distribution was significantly higher in the case of $\mathrm{scCO}_{2} / \mathrm{EtOH}$ with $\mathrm{D}_{\text {Pore }}=67 \mathrm{~nm}$ compared to the sample $\mathrm{FD} / \mathrm{t} \mathrm{BuOH}$ with an average value of $52 \mathrm{~nm}$. Supercritical drying consequently 
Fig. 1 Comparison of porous aerogels obtained by freeze-drying $(\mathrm{FD} / \mathrm{t} \mathrm{BuOH})$ and super-critical drying $\left(\mathrm{scCO}_{2} / \mathrm{EtOH}\right)$. The average particle size ( $\mathrm{D}_{\text {Particle }}$ ) was extracted from SEM micrograph analysis. Pore size distributions of the powders were measured by nitrogen sorption according to the theory of Barrett Joyner and Halenda (BJH) and thermoporosimetry. The average pore sizes $\left(\mathrm{D}_{\text {Pore }}\right)$ of the sample is highlighted in the pore size distribution. The surface area $\left(\mathrm{S}_{\mathrm{BET}}\right)$ was calculated from nitrogen sorption measurements according to the BET theory
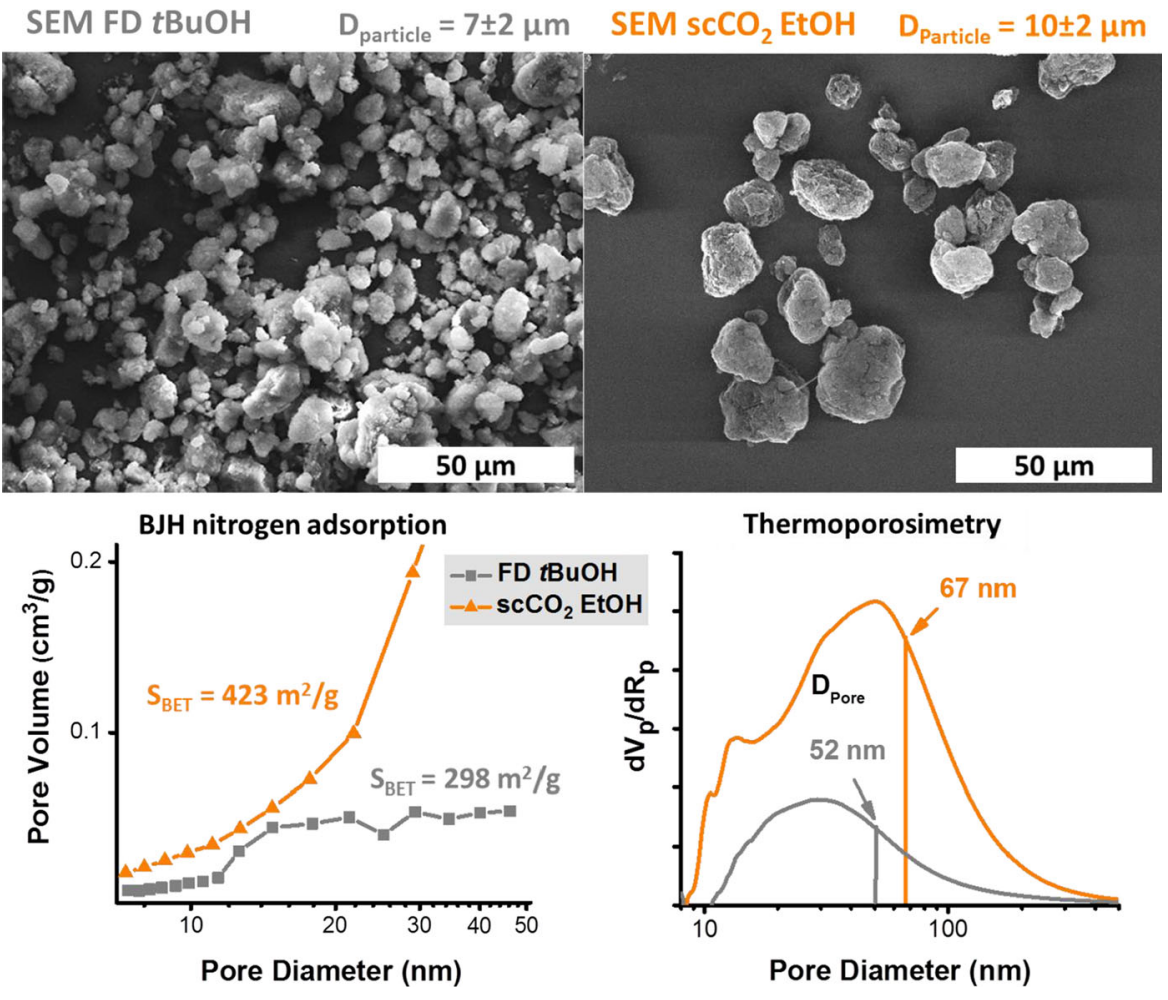

Fig. 2 The surfaces of the porous samples are energetically heterogeneous as shown in the plot of total surface energy against area increment. The Gutmann acid $\left(\mathrm{K}_{\mathrm{A}}\right)$ and base constants $\left(\mathrm{K}_{\mathrm{B}}\right)$ at a surface coverage of $0.01 \mathrm{n} / \mathrm{n}_{\mathrm{m}}$ show that the basic character is dominating on both samples. The high value of the work of cohesion reflects the high tendency of aggregation in the sample. The mean values of the dispersive $\left(\gamma_{s}^{D, 50}\right)$, specific $\left(\gamma_{s}^{A B, 50}\right)$ and total surface energy $\left(\gamma_{s}^{T, 50}\right)$ at $303 \mathrm{~K}$ are shown in the table at the top

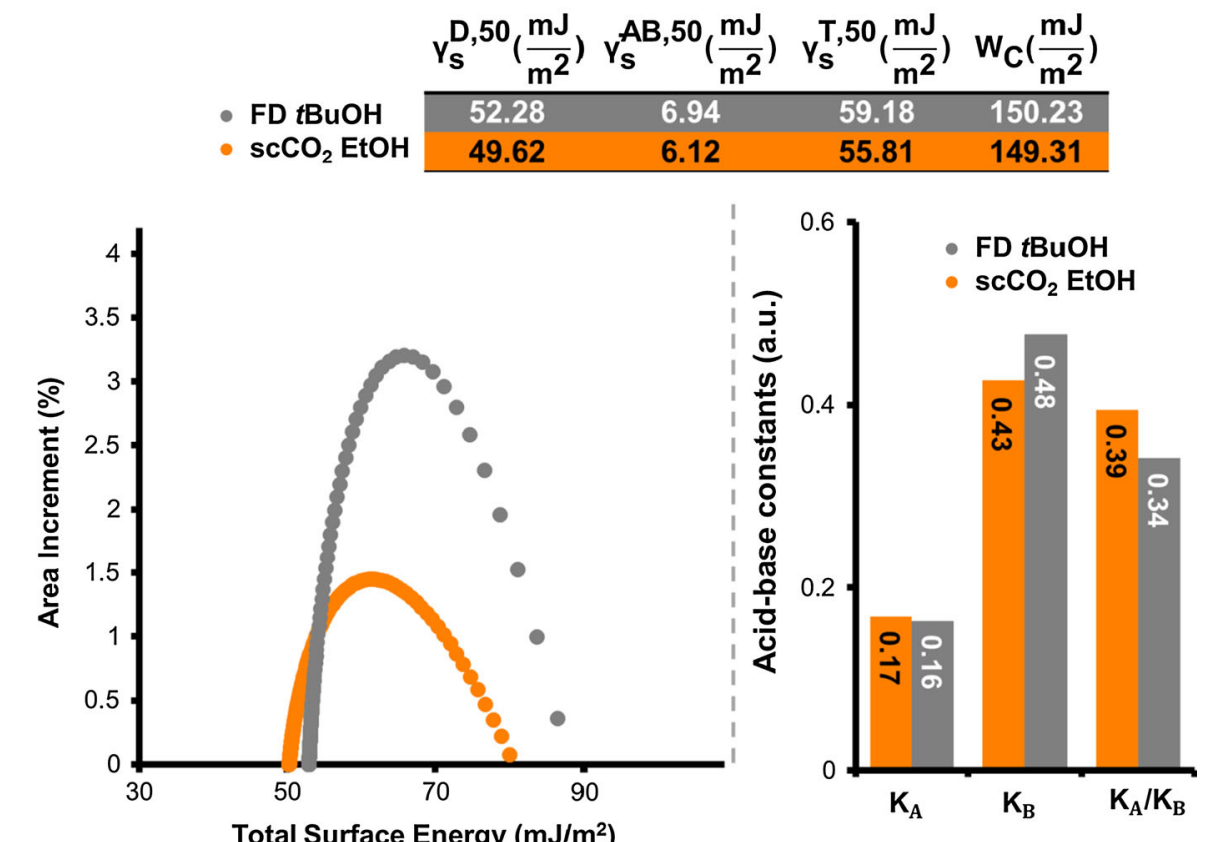

appeared to be the superior drying technique with regard to preserving the high surface area and the macroporosity of the cellulose II gel.
The pore size distribution obtained from nitrogen sorption experiments is emphasizing lower pore sizes, since it considers the mesoporous region only, and 

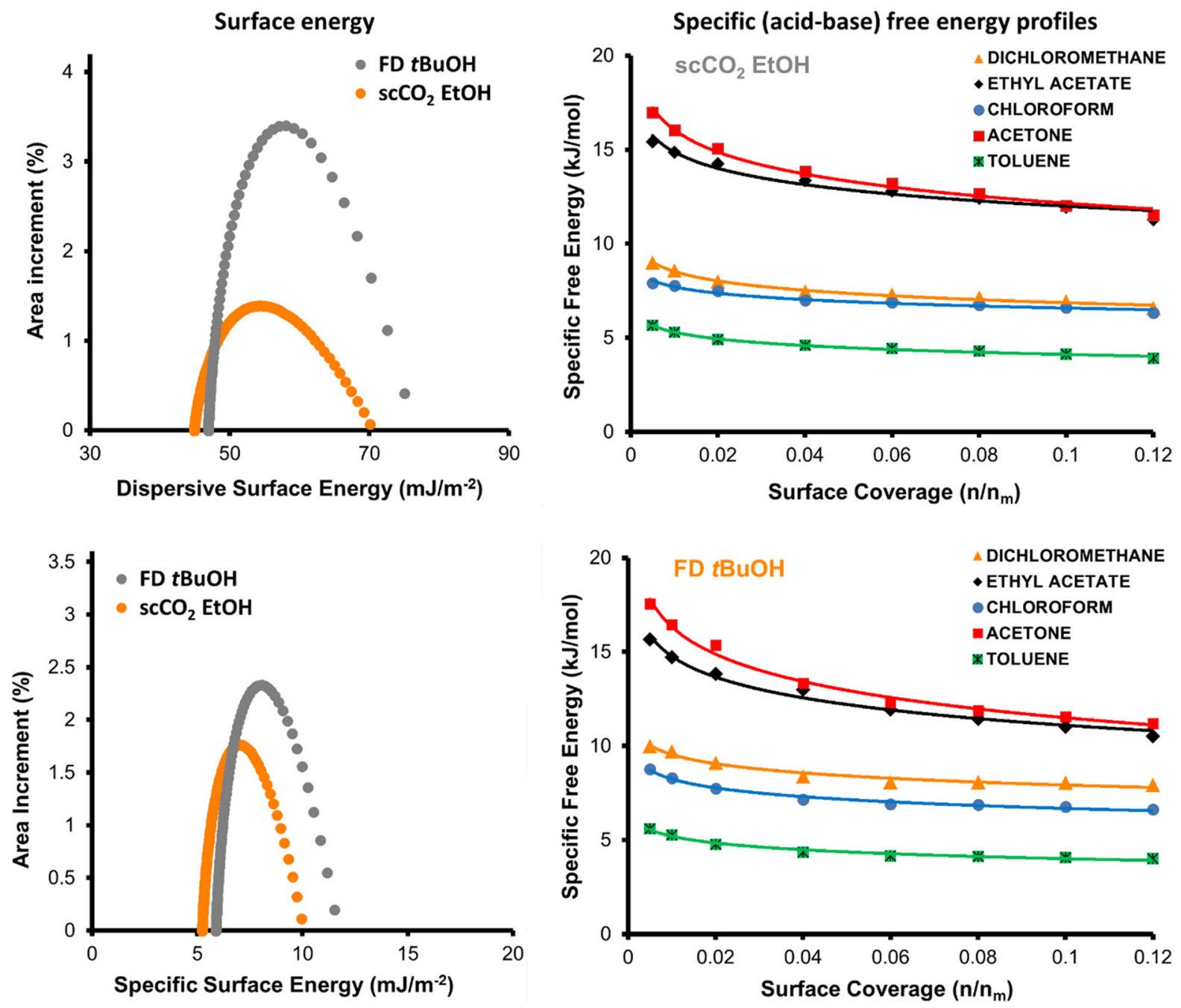

Fig. 3 Dispersive and acid-base (specific) surface energy against area increment. The specific free energy profiles of the amphoteric $\mathrm{scCO}_{2} / \mathrm{EtOH}$ and $\mathrm{FD} / \mathrm{tBuOH}$ sample is showing strongest interactions with the non-chlorinated polar probes: acetone and ethyl acetate

shows for both samples an increase of pore volume at the upper end of the mesoporous region. The macroporous region was analyzed by thermoporosimetry and-as shown in Fig. 1-there are also larger pores present, up to $300 \mathrm{~nm}$.

In order to represent the heterogeneity of the samples in a more illustrative manner, the surface energy distributions were obtained by a point-by-point integration of the surface energy profiles, resulting in plots of $\gamma_{s}^{T} \gamma_{s}^{D}$ and $\gamma_{s}^{A B}$ surface energy versus percentage of surface (area increment), as shown in Figs. 2 and 3 .

The dispersive term $\gamma_{s}^{D}$ is caused by non-polar longrange interactions (London forces) and the specific short-range (acid-base) $\gamma_{s}^{A B}$ term by polar interactions (hydrogen bonds) (Rjiba et al. 2007; Rückriem et al. 2010). Consistent with the Lindman hypothesis, both samples are amphoteric (Lindman et al. 2010) featuring a dominating dispersive term, $\gamma_{s}^{D, 50}=52.3 \mathrm{~mJ} / \mathrm{m}^{2}$ and $\gamma_{s}^{A B, 50}=6.9 \mathrm{~mJ} / \mathrm{m}^{2}(\mathrm{FD} / \mathrm{t} \mathrm{BuOH})$. The higher surface area and pore volume of $\mathrm{scCO}_{2} / \mathrm{EtOH}$ indicated already that supercritical drying is the less "destructive" drying method, which explains as well the less pronounced energetic heterogeneity of this sample, see Figs. 2 and 3. Nevertheless, FD/ $t \mathrm{BuOH}$ is more polar (higher $\gamma_{s}^{A B, 50}$ ), features higher dispersive $\gamma_{s}^{D, 50}$ and total surface energetics $\gamma_{s}^{T, 50}$ than $\mathrm{scCO}_{2} /$ $\mathrm{EtOH}$ and is thus more reactive (Thielmann 2004). In 
comparison to other cellulose substrates (Table S1), both powders feature higher dispersive surface energies than cotton (Kondor et al. 2015) and lyocell fibers (Tze et al. 2006) and are comparable to TEMPO-oxidized and genuine CNF (Peng et al. 2013; Gamelas et al. 2015).

The specific (acid-base) Gibbs free energy of desorption, $\Delta \mathrm{G}_{\mathrm{SP}}$, of polar solvents on both samples was also measured at different surface coverage (Fig. 3). Higher $\Delta \mathrm{G}_{\mathrm{SP}}$ values can be attributed to a higher concentration of polar surface groups or different surface groups with higher specific surface energy. Both samples showed strong interactions with all polar probes, but predominantly interacted with the carbonyl probes, acetone and ethyl acetate (Fig. 3). The rank order of the samples for decreasing $\Delta \mathrm{G}_{\mathrm{SP}}$ interactions is acetone, ethyl acetate, dichloromethane, chloroform and toluene.

The surface chemistry of the samples was assessed using the Gutmann acid $\left(\mathrm{K}_{\mathrm{A}}\right)$ and base $\left(\mathrm{K}_{\mathrm{B}}\right)$ numbers, determined with the following polar probes: dichloromethane, ethyl acetate, acetone, and chloroform. $\mathrm{K}_{\mathrm{A}}$ and $K_{B}$ values of the samples were calculated using the $\Delta \mathrm{G}_{\mathrm{SP}}$ values of polar probes at that particular surface coverage. Consistent with the literature (Tze et al. 2006; Pommet et al. 2008; Peng et al. 2013), the $K_{B}$ for both samples was consistently higher than $\mathrm{K}_{\mathrm{A}}$, indicating that the samples possess higher concentrations of electron-donating (basic) surface functional groups than electron-withdrawing (acidic) ones. The higher specific Gibbs Free Energy of acidic probe (like acetone) indicates the domination of electron donating groups on the surface.

In conclusion, both aerogels obtained from freezedrying and supercritical drying, featured comparable nanostructures and surface properties. Supercritical drying was superior in preserving the mesoporous and macroporous regions and yielded cellulose particles with a very high surface area of $423 \mathrm{~m}^{2} / \mathrm{g}$ and an average pore size of $35 \mathrm{~nm}$. The resulting $t \mathrm{BuOH}$ cryogel is more polar and more reactive with a total surface energy of $59 \mathrm{~mJ} / \mathrm{m}^{2}$, higher than the supercritically dried (EtOH) sample. Considering the fact that freeze-drying is significantly cheaper and far more widespread than the supercritical drying method, it is important to note that freeze-drying can be a viable alternative, if the high surface area is not the decisive factor. Otherwise, supercritical drying is the superior variant.
Acknowledgments The project is financed by the PhD School DokIn'Holz, funded by the Austrian Federal Ministry of Science, Research and Economy and Lenzing AG. Thomas Schmid is acknowledged for his support in the iGC measurements. Open access funding provided by University of Natural Resources and Life Sciences Vienna (BOKU).

Open Access This article is distributed under the terms of the Creative Commons Attribution 4.0 International License (http:// creativecommons.org/licenses/by/4.0/), which permits unrestricted use, distribution, and reproduction in any medium, provided you give appropriate credit to the original author(s) and the source, provide a link to the Creative Commons license, and indicate if changes were made.

\section{References}

Aegerter MA, Leventis N, Koebel MM (eds) (2011) Aerogels handbook. Springer, New York

Aulin C, Gällstedt M, Lindström T (2010) Oxygen and oil barrier properties of microfibrillated cellulose films and coatings. Cellulose 17:559-574. doi:10.1007/s10570-0099393-y

Beaumont M, Rennhofer H, Opietnik M et al (2016) Nanostructured cellulose II gel consisting of spherical particles. ACS Sustain Chem Eng 4:4424-4432. doi:10. 1021/acssuschemeng.6b01036

Cai J, Kimura S, Wada M et al (2008) Cellulose aerogels from aqueous alkali hydroxide-urea solution. ChemSusChem 1:149-154. doi:10.1002/cssc.200700039

Cai J, Liu S, Feng J et al (2012) Cellulose-silica nanocomposite aerogels by in situ formation of silica in cellulose gel. Angew Chem 124:2118-2121. doi:10.1002/ange. 201105730

Domingues RMA, Gomes ME, Reis RL (2014) The Potential of cellulose nanocrystals in tissue engineering strategies. Biomacromolecules 15:2327-2346. doi:10.1021/bm5005 $24 \mathrm{~s}$

Gamelas JAF, Pedrosa J, Lourenço AF, Ferreira PJ (2015) Surface properties of distinct nanofibrillated celluloses assessed by inverse gas chromatography. Coll Surf Physicochem Eng Asp 469:36-41. doi:10.1016/j.colsurfa. 2014.12.058

Ganesan K, Dennstedt A, Barowski A, Ratke L (2016) Design of aerogels, cryogels and xerogels of cellulose with hierarchical porous structures. Mater Des 92:345-355. doi:10. 1016/j.matdes.2015.12.041

Habibi Y, Lucia LA, Rojas OJ (2010) Cellulose nanocrystals: chemistry, self-assembly, and applications. Chem Rev 110:3479-3500. doi:10.1021/cr900339w

Han J, Zhou C, Wu Y et al (2013) Self-assembling behavior of cellulose nanoparticles during freeze-drying: effect of suspension concentration, particle size, crystal structure, and surface charge. Biomacromolecules 14:1529-1540. doi: $10.1021 / \mathrm{bm} 4001734$

Hayase G, Kanamori K, Abe K et al (2014) Polymethylsilsesquioxane-cellulose nanofiber biocomposite aerogels with high thermal insulation, bendability, and 
superhydrophobicity. ACS Appl Mater Interfaces 6:9466-9471. doi:10.1021/am501822y

Kobayashi Y, Saito T, Isogai A (2014) Aerogels with 3d ordered nanofiber skeletons of liquid-crystalline nanocellulose derivatives as tough and transparent insulators. Angew Chem Int Ed. doi:10.1002/anie.201405123

Kondor A, Quellet C, Dallos A (2015) Surface characterization of standard cotton fibres and determination of adsorption isotherms of fragrances by IGC: surface characterization of cotton and adsorption of fragrances by IGC. Surf Interface Anal 47:1040-1050. doi:10.1002/sia.5811

Lavoine N, Bras J, Desloges I (2014) Mechanical and barrier properties of cardboard and 3D packaging coated with microfibrillated cellulose. J Appl Polym Sci. doi:10.1002/ app.40106

Li K, Song J, Xu M et al (2014) Extraordinary reinforcement effect of three-dimensionally nanoporous cellulose gels in poly( $\varepsilon$-caprolactone) bionanocomposites. ACS Appl Mater Interfaces 6:7204-7213. doi:10.1021/am500337p

Lin N, Huang J, Dufresne A (2012) Preparation, properties and applications of polysaccharide nanocrystals in advanced functional nanomaterials: a review. Nanoscale 4:3274-3294. doi:10.1039/C2NR30260H

Lindman B, Karlström G, Stigsson L (2010) On the mechanism of dissolution of cellulose. J Mol Liq 156:76-81. doi:10. 1016/j.molliq.2010.04.016

Männer J, Opietnik M, Innerlohinger J et al (2015) Cellulose suspension, method for the production and use thereof. International patent WO/2015/054712

Markstedt K, Mantas A, Tournier I et al (2015) 3D bioprinting human chondrocytes with nanocellulose-alginate bioink for cartilage tissue engineering applications. Biomacromolecules 16:1489-1496. doi:10.1021/acs.biomac.5b00 188

Nemoto J, Saito T, Isogai A (2015) Simple freeze-drying procedure for producing nanocellulose aerogel-containing, high-performance air filters. ACS Appl Mater Interfaces 7:19809-19815. doi:10.1021/acsami.5b05841

Peng Y, Gardner DJ, Han Y (2012) Drying cellulose nanofibrils: in search of a suitable method. Cellulose 19:91-102. doi:10.1007/s10570-011-9630-z
Peng Y, Gardner DJ, Han Y et al (2013) Influence of drying method on the surface energy of cellulose nanofibrils determined by inverse gas chromatography. J Colloid Interface Sci 405:85-95. doi:10.1016/j.jcis.2013.05.033

Pommet M, Juntaro J, Heng JYY et al (2008) Surface modification of natural fibers using bacteria: depositing bacterial cellulose onto natural fibers to create hierarchical fiber reinforced nanocomposites. Biomacromolecules 9:16431651. doi: $10.1021 / \mathrm{bm} 800169 \mathrm{~g}$

Rämänen P, Penttilä PA, Svedström K et al (2012) The effect of drying method on the properties and nanoscale structure of cellulose whiskers. Cellulose 19:901-912. doi:10.1007/ s10570-012-9695-3

Rjiba N, Nardin M, Dréan J-Y, Frydrych R (2007) A study of the surface properties of cotton fibers by inverse gas chromatography. J Colloid Interface Sci 314:373-380. doi:10. 1016/j.jcis.2007.05.058

Rückriem M, Inayat A, Enke D et al (2010) Inverse gas chromatography for determining the dispersive surface energy of porous silica. Coll Surf Physicochem Eng Asp 357:21-26. doi:10.1016/j.colsurfa.2009.12.001

Saito T, Uematsu T, Kimura S et al (2011) Self-aligned integration of native cellulose nanofibrils towards producing diverse bulk materials. Soft Matter 7:8804-8809. doi:10. 1039/C1SM06050C

Sehaqui H, Zhou Q, Berglund LA (2011) High-porosity aerogels of high specific surface area prepared from nanofibrillated cellulose (NFC). Compos Sci Technol 71:1593-1599. doi:10.1016/j.compscitech.2011.07.003

Thielmann F (2004) Introduction into the characterisation of porous materials by inverse gas chromatography. J Chromatogr A 1037:115-123. doi:10.1016/j.chroma.2004.03. 060

Tze WTY, Wålinder MEP, Gardner DJ (2006) Inverse gas chromatography for studying interaction of materials used for cellulose fiber/polymer composites. J Adhes Sci Technol 20:743-759. doi:10.1163/156856106777638644

Wheeler EE, Gavin JB, Seelye RN (1975) Freeze-drying from tertiary butanol in the preparation of endocardium for scanning electron microscopy. Stain Technol 50:331-337 